pattern $(41.3 \%$ and $34.9 \%$ ), fatigue $(35.3 \%$ and $28.6 \%)$, and loss of interest in sex $(21.7 \%$ and $21.9 \%)$, for AS and PsA, respectively.

In univariate analysis (Table 1), female gender $(\mathrm{OR}=1.73)$, unemployment due to disability $(O R=3.06)$ or other reasons $(O R=2.38)$, increased BASDAI $(O R=1.40)$, increased BASFI $(O R=1.33)$, and increased morning stiffness $(O R=1.01)$ were significantly associated [all $P<0.001$ except gender $(\mathrm{P}=0.009)$ ] with baseline depression among AS patients. For PsA, significantly associated parameters included female sex $(O R=2.35 ; P=0.001)$, unemployment due to disability $(\mathrm{OR}=3.57 ; \mathrm{P}<0.001)$, increased TJC $(\mathrm{OR}=1.05 ; \mathrm{P}=0.009)$, increased $\mathrm{PtGA} \quad(\mathrm{OR}=1.03 ; \mathrm{P}<0.001)$ and increased morning stiffness $(O R=1.01 ; P=0.010)$. Weak correlations $(P<0.05)$ were observed between the BDI score and BASFI ( $r=0.425)$, BASDAI $(r=0.375)$, morning stiffness $(r=0.285)$, and number of EAMs $(r=0.114)$ for $A S$; and TJC ( $r=0.155)$, MDGA ( $r=0.132)$, and PtGA $(r=0.451)$ for PsA. In multivariate regression analysis for $A S$, higher $B A S F I \quad(O R=1.32$; $\mathrm{P}<0.001)$, female sex $(O R=1.89 ; \mathrm{P}=0.007)$ and being unemployed due to other reasons $(O R=1.91 ; P=0.017)$; and, for $P s A$, lower baseline disease duration $(\mathrm{OR}=0.97 ; \mathrm{P}=0.018)$, and higher $\mathrm{PtGA}(\mathrm{OR}=1.04 ; \mathrm{P}<0.001)$ were identified as significant independent predictors of baseline depression. Conclusion: Depression in AS and PsA patients was common in this real-world cohort. Female sex, unemployment, and higher disease activity for AS, and shorter disease duration along with higher PtGA for PsA were significant independent predictors of depression.

Disclosure of Interests: Louis Bessette Grant/research support from: Amgen, BMS, Janssen, Roche, UCB, AbbVie, Pfizer, Merck, Celgene, Sanofi, Lilly, Novartis, Consultant for: Amgen, BMS, Janssen, Roche, UCB, AbbVie, Pfizer, Merck, Celgene, Sanofi, Lilly, Novartis, Speakers bureau: Amgen, BMS, Janssen, Roche, UCB, AbbVie, Pfizer, Merck, Celgene, Sanofi, Lilly, Novartis, Majed Khraishi Consultant for: AbbVie, Speakers bureau: AbbVie, Viktoria Pavlova Grant/research support from: UCB, Consultant for: Amgen, Abbvie, BMS, Janssen, Lilly, Merk, Novartis, Roche, UCB, Pfizer, Speakers bureau: Amgen, Abbvie, BMS, Janssen, Lilly, Merk, Novartis, Roche, UCB, Pfizer, Jacqueline Stewart Consultant for: Pfizer, Abbvie, Amgen, Celgene, Roche, Novartis, Merck, Valencia P. Remple Shareholder of: AbbVie, Employee of: AbbVie

DOI: 10.1136/annrheumdis-2019-eular.5693

\section{SAT0319 OBESITY AND ASSOCIATED FACTORS IN NORWEGIAN AXIAL SPONDYLOARTHRITIS PATIENTS. RESULTS FROM THE EUROPEAN MAP OF AXIAL SPONDYLOARTHRITISSURVEY}

Christian Bindesbø $\|^{1}$, Marco Garrido-Cumbrera ${ }^{2,3}$, Gunnstein Bakland ${ }^{4}$, Hanne Solveig Dagfinrud ${ }^{5}$,EMAS working group. ${ }^{1}$ Novartis Pharma AG, Norway, Oslo, Norway, ${ }^{2}$ Universidad de Sevilla, Health and Territory Research (HTR), Sevilla, Spain; ${ }^{3}$ Spanish Federation of Spondyloarthritis Associations (CEADE), Madrid, Spain; ${ }^{4}$ University Hospital of Northern Nonway, Department of Rheumatology, Tromsø, Norway, ${ }^{5}$ Diakonhjemmet Hospital, National Advisory Unit on Rehabilitation in Rheumatology, Oslo, Norway

Background: Obesity increases the risk of developing chronic inflammatory diseases, including axial spondyloarthritis $(\operatorname{axSpA})^{1,2}$. Information about how obesity correlates with disease activity in $\operatorname{axSpA}$ patients is limited.

Objectives: The objective of this survey was to investigate the association between body mass index (BMI) and patient reported disease activity in Norwegian axSpA patients.

Methods: The European Map of Axial Spondyloarthritis (EMAS), conducted from July 2017 to February 2018, was a cross-sectional on-line survey of 2,846 unselected patients with self-reported axSpA from 13 European countries (Austria, Belgium, France, Germany, Italy, Netherlands, Norway, Russia, Slovenia, Spain, Sweden, Switzerland, and the UK). Participants were recruited through an on-line panel and patient organizations. This analysis is based on data from the 509 Norwegian respondents. Sociodemographic variables (age, gender, BMI, comorbidity), and disease related variables (Bath Ankylosing Spondylitis Disease Activity Index (BASDAI) (0-10), self-reported spinal stiffness (3-12) and General Health Questionnaire (0-12) (GHQ-12)) were reported.

Results: Out of the 509 Norwegian participants with axSpA, 69.7\% (N:355) were women. The mean age was $48 \pm 12$ years, mean disease duration was $5.3 \pm 2.0$ years, $82.3 \%$ were HLA-B27 positive, and $55.2 \%$ (N:281) were university educated. In total, $35 \%(\mathrm{~N}: 180)$ of the participants were normal/underweight (BMI < 25) and 65\% (N:329) were overweight/obese (BMI >25). The mean (sd) disease activity, as measured by BASDAl (010), was 5.3 \pm 2.0 . Overweight/obese patients reported significantly higher disease activity (BASDAI 5.5 \pm 1.9 ) compared to normal weight patients (BASDAI 5.0 \pm 2.1). Moreover, being overweight/obese was associated with a significantly higher degree of spinal stiffness, number of comorbidities and a numerically, but not significantly, higher GHQ-12 score. There was no significant differences in alcohol consumption, smoking, or prevalence of inflammatory bowel disease (Crohn's disease or ulcerative colitis).

Conclusion: Norwegian overweight/obese axSpA patients from the EMAS survey report significantly higher disease activity, spinal stiffness and number of comorbidities. The results highlight the serious impact of overweight and obesity on the health status of axSpA patients. Therefore obesity should be considered as a preventable risk factor and within the disease management of axSpA

\section{REFERENCES}

[1] Maas, et al. Obesity Is Common in Axial Spondyloarthritis and Is Associated with Poor Clinical Outcome. The Journal of Rheumatology 2016; 43 (2) 383-387.

[2] Shan, et al. Impact of obesity on the efficacy of different biologic agents in inflammatory diseases: A systematic review and meta-analysis. Joint Bone Spine. 2018, in press.

Acknowledgement: EMAS was funded by Novartis Pharma AG Disclosure of Interests: Christian Bindesbøll Employee of: I currently work in Novartis Pharma AG Norway as listed in my affiliations, Marco Garrido-Cumbrera Consultant for: Honoraria from Novartis as steering committe of this survey, Gunnstein Bakland: None declared, Hanne Solveig Dagfinrud Consultant for: Honoraria from Novartis as a steering committee member on this survey

DOI: 10.1136/annrheumdis-2019-eular.7196

\begin{tabular}{|l|l}
\hline SAT0320 & FREQUENCY AND CHARACTERISTICS OF \\
INFLAMMATORY BOWEL DISEASE IN \\
SPONDYLOARTHRITIS WITH BIOLOGICAL THERAPY. \\
STUDY OF 270 PATIENTS FROM THE SAME CENTER
\end{tabular}

I. Calvo $^{1}$, O. Ibarguengoitia ${ }^{1}$, D M Montero $^{1}$, L Vega $^{1}$, L María $^{1}$, M E. Ruiz ${ }^{1}$, I Torre ${ }^{1}$, O Fernandez $^{1}$, J M. Blanco ${ }^{1}$, A R. Inchaurbe ${ }^{1}$, Clara Pérez ${ }^{1}$, Eduardo Cuende ${ }^{1}$, Natalia Rivera ${ }^{1}$, María Jesús Allande ${ }^{1}$, Helena Ugarte ${ }^{1}$, Iñigo Gorostiza ${ }^{2}$, E Galindez ${ }^{1} .{ }^{1}$ Basurto University Hospital, Rheumatology, Bilbao, Spain; ${ }^{2}$ Basurto University Hospital, Research Unit, Bilbao, Spain

Background: Inflammatory bowel disease (IBD) is an extra-articular manifestation that can appear in spondyloarthritis (SpA), as well as uveitis and psoriasis. Its prevalence is $5-10 \%$, although subclinical intestinal inflammation has been found in up to $60 \%$. Biological therapy (BT) can be the treatment for IBD or produce it paradoxically. Fecal calprotectin $(F C)$ is an intestinal inflammation marker, useful for early diagnosis and monitoring disease activity.

Objectives: To describe the frequency and characteristics of IBD in SpA with BT.

Methods: Descriptive and retrospective study (January 2003-January 2019) of patients with SpA that develop IBD in a single center. Epidemiological variables, type of $\mathrm{SpA}$, presence of $\mathrm{IBD}$ and its characteristics, levels of $\mathrm{FC}$, presence of $\mathrm{BT}$ at IBD onset and treatment received were registered. For the analysis, frequencies and percentages were used in qualitative variables and mean \pm standard deviation (SD) in quantitative. Statistical analysis was performed with IBM SPSS v.23.

Results: We studied 270 patients with SpA, 70.4\% male with a mean age of $39.9 \pm 12$ years. The subtypes of $\mathrm{SpA}$ were: ankylosing spondylitis (AS) $(n=133 ; 49.3 \%)$, psoriatic arthritis (PsA) ( $n=116 ; 43 \%)$, undifferentiated $\operatorname{SpA}(\mathrm{n}=16 ; 5.9 \%)$, SpA non- $\mathrm{Rx}$ axial $(\mathrm{n}=3 ; 1.1 \%)$ and reactive arthritis $(n=2 ; 0.7 \%)$

IBD was observed in 25 patients $(9.26 \%), 80 \%$ male. At the time of IBD onset, they had a mean age of $39.12 \pm 9.8$ years, the mean ESR was $31.15 \pm 24 \mathrm{~mm} 1^{\mathrm{a}} \mathrm{h}, \mathrm{CRP} 2.7 \pm 2 \mathrm{mg} / \mathrm{dL}$ and BASDAl 4.6. 16 patients had AS, 6 PsA and 3 undifferentiated SpA. TABLE 1.

Regarding Spa diagnosis, IBD appeared after in 15 patients with an average time of development of $8.39 \pm 8$ years, before in 7 and was simultaneous in 3 . The subtypes of IBD were: Crohn's disease (CD) in 13 patients, ulcerative colitis (UC) in 9 and indeterminate colitis (IC) in 3 . The FC was $>200 \mu \mathrm{g} / \mathrm{g}$ in 17 patients $(68 \%)$, normal $(<50 \mu \mathrm{g} / \mathrm{g})$ in 1 and between $50-200 \mu \mathrm{g} / \mathrm{g}$ in 7 . The incidence rate adjusted for follow-up of the 25 cases was 7.7 cases/1000 patients-year.

At the time of the IBD onset, 6 patients were with BT: Etanercept (ETN) $(n=2)$, Infliximab (IFX) $(n=1)$, Adalimumab (ADA) $(n=1)$, Secukinumab (SCK) $(n=1)$ and Ustekinumab (UST) $(n=1)$. The BT had been initiated the previous 12 months in 5 of them. The incidence rate adjusted for follow-up of the 6 cases of IBD after BT was 1.83 cases/1000 patient-years. TABLE 2. The treatment of the 25 patients with IBD was mesalazine $(n=15)$, oral corticoid $(n=5)$, methotrexate $(n=7)$ and BT in all cases. The BT was: 
ADA $(n=11 ; 44 \%)$, IFX $(n=6 ; 24 \%)$, UST $(n=3 ; 12 \%)$, golimumab $(n=3$; $12 \%)$, SCK $(n=1 ; 4 \%)$ and vedolizumab $(n=1 ; 4 \%)$. The indication was intestinal in 4 patients, joint in 8 and both in 13 .

The clinical and analytical evolution in all patients was satisfactory, with a mean ESR of $11.6 \pm 9 \mathrm{~mm} 1^{\mathrm{a}} \mathrm{h}, \mathrm{CRP} 0.6 \pm 0.3 \mathrm{mg} / \mathrm{dL}$ and BASDAI 2 in the last control, after an average time of evolution of $12.5 \pm 9.3$ years.

Conclusion: In this series, IBD was observed in $9.26 \%$ of patients with $\mathrm{SpA}$ of which $64 \%$ were AS. The most frequent form was $\mathrm{CD}$ and it was diagnosed after $\mathrm{SpA}$ in $60 \%$ of the cases. 6 patients were with BT at the time of IBD onset. High FC $(>200 \mu \mathrm{g} / \mathrm{g})$ was observed in the majority of patients.

Therefore, we recommend assessing the presence of digestive manifestations (abdominal pain, weight loss or diarrhea) in patients with SpA due to their possible association with IBD. The FC is a useful tool in these patients.

TABLE 1. CHARACTERISTICS OF IBD IN SPA SUBTYPES

\begin{tabular}{|c|c|c|c|c|}
\hline & $\begin{array}{c}\text { AS } \\
(n=16,64 \%)\end{array}$ & $\begin{array}{c}\text { PsA } \\
(n=6,24 \%)\end{array}$ & $\underset{(n=3,12 \%)}{\text { uSpa }}$ & TOTAL $=25$ \\
\hline MEN/WOMEN & $14 / 2$ & $4 / 2$ & $2 / 1$ & $\begin{array}{c}20 / 5 \\
(80 \% / 20 \%)\end{array}$ \\
\hline $\begin{array}{l}\text { AGE AT IBD DX } \\
\text { (average in years) }\end{array}$ & 37.56 & 45.8 & 34 & 39.12 \\
\hline HLA B27+ (n, pationts) & 13 & 1 & 1 & 15 \\
\hline CD/UC/IC (n, pationts) & $9 / 6 / 1$ & 2/2/2 & $2 / 1 / 10$ & $\begin{array}{c}13 / 9 / 3 \\
(52 \% / 36 \% / 12 \%)\end{array}$ \\
\hline ESR (average in $\mathrm{mm}^{1} \mathrm{P}^{\mathrm{h}}$ ) & 30.07 & 39.75 & 21.5 & 31.15 \\
\hline CPR (avorago in $\mathrm{mg} / \mathrm{dL}$ ) & 2.44 & 3.08 & 3.42 & 2.7 \\
\hline $\begin{array}{ll}F C \text { (avorage in } \mu \mathrm{g} g \mathrm{~g}) \\
\end{array}$ & 369.2 & 409.67 & 1009 & 459.29 \\
\hline 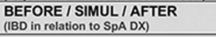 & 6/2/8 & $0 / 0 / 6$ & 1/1/1/1 & $\begin{array}{c}7 / 3 / 15 \\
(28 \% / 12 \% / 60 \%)\end{array}$ \\
\hline BT AT IBD DX (n, pationts) & 3 & 2 & 1 & 6 \\
\hline BT & $\begin{array}{l}\operatorname{ETN}(n=1), \\
\operatorname{IFX}(n=1), \\
\operatorname{SCK}(n=1)\end{array}$ & $\begin{array}{l}\text { ADA }(n=1), \\
\text { UST (n=1), }\end{array}$ & ETN $(n=1)$ & 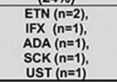 \\
\hline
\end{tabular}

TABLE 2. BT IN 270 PATIENTS WITH SPA.

\begin{tabular}{|c|c|c|c|}
\cline { 2 - 4 } \multicolumn{1}{c|}{} & Patients $(\mathbf{n})$ & $\begin{array}{c}\text { IBD development } \\
\text { after BT }(\mathbf{n})\end{array}$ & $\begin{array}{c}\text { IBD development } \\
\text { after BT (\%) }\end{array}$ \\
\hline ETN & 57 & 2 & $3.50 \%$ \\
\hline ADA & 98 & 1 & $1.02 \%$ \\
\hline IFX & 36 & 1 & $2.78 \%$ \\
\hline SCK & 22 & 1 & $4.54 \%$ \\
\hline UST & 15 & 1 & $6.67 \%$ \\
\hline CZP & 25 & 0 & $0 \%$ \\
\hline GLM & 15 & 0 & $0 \%$ \\
\hline VDZ & 2 & 0 & $0 \%$ \\
\hline TOTAL & 270 & 6 & $2.22 \%$ \\
\hline
\end{tabular}

BT: biological therapy, IBD: inflammatory bowel disease, ETN: etanercept, ADA: adalimumab, IFX: infliximab, SCK: secukinumab, UST: ustekinumab, CZP: certolizumab, GLM: golimumab, VDZ: vedolizumab

Disclosure of Interests: None declared

DOI: 10.1136/annrheumdis-2019-eular.4427

\section{SAT0321 CARDIOVASCULAR EVENTS IN SPONDYLOARTHRITIS A META-ANALYSIS}

Jihyoun Kim, In Ah Choi. Chungbuk National University Hospital, Rheumatology department, internal medicine, Cheoungju-si, Chungcheongbuk-do, Korea, Rep. of (South Korea)

Background: Several studies have demonstrated the possibility of increased risk of cardiovascular disease in patients with inflammatory arthritis such as anklyosing spondylitis and rheumatoid arthritis. In recent years, studies using population -based cohort and insurance claim data have been actively conducted.

Objectives: To compare risks for cardiovascular disease including myocardial infarction (MI), ischemic heart disease (IHD), stroke and mortality of spondyloarthritis compared to general population using large-scale data. Methods: A systematic search was performed in MEDLINE, EMBASE with additional manual searches for studies associated with spondyloarthritis published between January 1997 and October 2018. All search screening and data collection were performed independently by two reviewers. We calculated the incidences of $\mathrm{MI}$, IHD, stroke and mortality in a meta-analysis of proportion and determined risk ration (RR) by Mante-Haenszel method.
Results: We identified total 495 articles and 16 articles met criteria for meta-analysis including 13 anklyosing spondylitis (AS) studies, 3 psoriatic arthritis (PsA) studies and 1 undifferentiated spondyloarthritis study. The articles were based on large-scale data such as national population cohort or insurance claim data. A meta-analysis result showed a significant increase in the risk of $\mathrm{Ml}(\mathrm{RR}=1.38 ; 95 \% \mathrm{Cl} 1.18$ to 1.61$)$, and stroke $(R R=2.04 ; 95 \% \mathrm{Cl} 1.11$ to 3.78$)$ in spondyloarthritis patients com pared to general population. However, mortality related with cardiovascular disease $(R R=1.19 ; 95 \% \mathrm{Cl} 0.96$ to 1.48$)$ and total mortality $(R R=1.31$ $95 \% \mathrm{Cl} 0.8$ to 2.15 ) results did not show significant increases in spondy loarthritis patients.

Conclusion: Our meta-anaylsis results showed that the the risk of $M$ and stroke significantly increased although mortality associated with cardiovasular (CV) disease and overall mortality did not increase in spondyloarthritis compared to general population. These findings support the reduction of inflammation as well as the management of traditional cardiovascular disease risk factors may reduce $\mathrm{CV}$ risk in patients with spondyloarthritis.

\section{REFERENCES}

[1] Szabo SM, Levy AR, Rao SR, et al. Increased risk of cardiovascular and cerebrovascular diseases in individuals with ankylosing spondylitis: a population-based study. Arthritis Rheum 2011; 62: 3294-304

[2] Park CJ, Choi YJ, Kim JG, et al. Association of acute myocardial infarction with ankylosing spondylitis: a nationwide longitudinal cohor study. Journal of Clinical Neuroscience 2018; 56: 34-37.

[3] Bengtsson, K, Forsblad-d'Elia H, Lie E, et al. Are ankylosing spondylitis, psoriatic arthritis and undifferentiated spondyloarthritis associated with an increased risk of cardiovascular events? A prospective nationwide population-based cohort study. Arthritis Res Ther 2017; 19:102

Disclosure of Interests: None declared

DOI: 10.1136/annrheumdis-2019-eular.6597

\section{SAT0322 AXSPA PATIENTS WITH SYMPTOM ONSET $<30$ YEARS HAVE MORE STRUCTURAL LESIONS ON MRI OF THE SACROILIAC JOINTS WHEN FULFILLING THE MODIFIED NEW YORK CRITERIA}

1,2 Manouk de Hooge, Ann-Sophie De Craemer ${ }^{1,2}$, Thomas Renson ${ }^{1,2}$ Philippe Carron ${ }^{1,2}$, Liselotte Deroo ${ }^{1,2}$, Dirk Elewaut ${ }^{1,2}$, Filip van den Bosch ${ }^{1,2} .{ }^{1} U Z$ Gent, Ghent, Belgium; ${ }^{2}$ VIB Inflammation Research Center, Ghent, Belgium

Background: The modified New York criteria (mNY) combine clinical symptoms with radiographic sacroilitis on conventional pelvic radiographs (X-SI) classifying radiographic axial SpA patients ( $r$-axSpA). AxSpA is known to typically start in the third era of life but there is a diagnostic delay of \pm 7 years. As the mNY criteria classify the most typical and severe expression of axSpA it is suggested that the mNY criteria are less useful in younger patients.

Objectives: To explore the diagnostic utility of the mNY criteria in newly diagnosed axSpA patients with a symptom onset $<30$ years. In addition, describe the extent of lesions on MRI of the sacroiliac joints (MRI-SI) in $\mathrm{mNY}$ positive $(\mathrm{mNY}+)$ patients with a symptom onset $<30$ years.

Methods: This study involved newly diagnosed axSpA patients, age $>18$ years, from a Belgian (Be-Giant) cohort. Patients underwent diagnostic tests involving clinical examination, lab tests, and imaging assessment containing an X-SI and an MRI-SI. mNY criteria was assessed on X-SI. MRI-SI reads contained the assessment of inflammatory lesions according to the Spondyloarthritis Research Consortium of Canada (SPARCC) scoring method and erosions, fatty lesions (FL), sclerosis, ankylosis using an adapted method of the SPARCC. Also, the ASAS definition of a positive MRI-SI was evaluated. T1-weighted and STIR images were viewed simultaneously. X-SI and MRI-SI were evaluated independently by 3 trained readers who were also blinded for clinical features. Imaging scores (X-SI grading according to the $\mathrm{mNY}$ criteria and $\mathrm{mNY}$ fulfillment, and MRI-SI lesion scores) were calculated as 2 out of 3 reader scores.

Results: In the 173 patients with available X-SI, the average age at symptom onset was 27.4 years old. In $114 / 173$ (65.9\%) patients, the symptom onset was below 30 years. Of those, 11 (9.6\%) patients fulfilled the mNY criteria. Seven of the $11(63.6 \%)$ patients that were $\mathrm{mNY}+$ were male, which was slightly lower than in the mNY- patients $(n=55$; $53.4 \%)$. The presence of HLA-B27 was comparable between $\mathrm{mNY}+$ and mNY- patients; $8(72.7 \%)$ patients and $82(79.6 \%)$ patients, respectively. Average $\mathrm{X}$-SI grading in $\mathrm{mNY}$ + patients was $4.7 \pm 1.3$ (on a scale from 0 8 ) and in mNY negative (mNY-) patients $(n=103)$ the average $X-S I$ grading was 1.1 1 1.1. When looking at the MRI-SI assessment, 8/11 mNY 